\title{
Septal lesions and male rat copulatory behavior?
}

\author{
EDWARD D. GOODMAN, ${ }^{2}$ BRADFORD \\ N. BUNNELL, ${ }^{3}$ DONALDA.DEWSBURY, \\ and $B O B$ BOLAND, Center for Neuro- \\ biological Sciences, University of Florida, \\ Gainesville, Fla. 32601
}

Three groups of male rats, septals, control operates, and normal controls, were given copulatory tests to a satiety criterion. No significant differences in copulatory behavior between the septals and control operates were found.

Limbic insult has been shown to produce alteration in the copulatory behavior of male rats when lesions are made in the amygdala (Bermant et al, 1968), hippocampus (Bermant et al, 1968; Dewsbury et al, 1968) and cingulate cortex (Larsson, 1962; Bunnell et al, 1966a). In view of the intimate anatomical connections between limbic system structures and because MacLean \& Ploog (1962) have shown that the septal area is one of the sites from which penile erection may be elicited by electrical stimulation, it might be expected that lesions of the septal nuclei would affect male copulatory behavior. Heimer \& Larsson (1967) have reported, in a brief descriptive note, that septal lesions do not have such an effect. However, Michal (1965) found that septal lesions lead to increased pursuit of females but that the behavioral transition between courtship and mounting was partially blocked.

In the present study, the copulatory behavior of male rats with bilateral lesions of the septal region was compared with that of normals and operated controls. Ss were tested to a behavioral satiety criterion in order to see if there was any interaction between experimental conditions and sexual behavior over copulatory series.

\section{SUBJECTS}

The Ss were 25 male Long-Evans rats, approximately 120 days of age at the first test. All had been adapted to the test arenas and had received one positive 3 -h copulation test prior to the experiment. Thirty-six experienced females of the same strain and 150 days of age at the first test served as partners in the copulation tests.

\section{APPARATUS}

Tests were conducted in four Plexiglas arenas 32 in. in diam and 26 in. high. The arenas were placed on wooden bases covered with a commercially produced litter. Copulatory events were recorded manually on an Esterline-Angus operations recorder.

\section{SURGICAL AND HISTOLOGICAL PROCEDURES}

Anesthesia for surgery was obtained by i.p. injection of sodium pentobarbital $(60 \mathrm{mg} / \mathrm{kg}) ; .20 \mathrm{cc}$ of $1 / 120 \mathrm{~g}$ atropine sulphate was used to reduce postoperative respiratory complications. Bilateral RF septal lesions were placed stereotaxically. Sham controls received the same operation except that the electrode was lowered only to the level of the corpus callosum and no current was passed. After testing, all operated Ss were sacrificed with an overdose of sodium pentobarbital and perfused with saline and $10 \%$ formalin. Brains were embedded in celloidin, sectioned at 30 micra and every fifth section mounted and stained with cresyl violet.

\section{TESTING PROCEDURES}

The rats were maintained on a reversed light-dark cycle in which the lights came on at midnight and went off at noon. All copulation tests were conducted in the last half of the dark phase under minimal illumination.

All rats received two preoperative copulation tests separated by a 2-week interval. On the basis of data from these tests, three groups were formed which were matched on ejaculation frequencies and ejaculation latencies in the first series (cf. below). The three groups received septal lesions, control operations, or no operation. After losses in surgery, there were eight $S$ s in the septal and normal control groups and seven $\mathrm{Ss}$ in the control operation group.

Postoperative testing began 8 to 12 days after the operations. Each rat received two postoperative tests separated by 2 weeks.

For the copulation tests, four males were placed in adjacent test arenas with two Os present. Five minutes later, females were placed in the arenas and testing was begun. If no intromissions occurred within $15 \mathrm{~min}$ the test was scored as negative. Otherwise, tests were continued to a satiety criterion of $30 \mathrm{~min}$ without an intromission or $2 \mathrm{~h}$ without an ejaculation.

Rat copulatory behavior occurs in bouts or series of vaginal intromissions with each series terminated by an ejaculation. The following measures, patterned after those of Beach \& Jordan (1956), were determined: mount latency (ML)-latency from the introduction of the female to the first mount; intromission latency (IL)-latency to the first intromission; ejaculation latency (EL)-latency from the first intromission of a series to the ejaculation; intromission frequency (IF)-the number of intromissions in a series; mount frequency (MF)-the number of mounts without intromission in each series; mean inter-intromission in terval (MIII)-the mean interval separating the intromissions of a series; post-ejaculatory interval (PEI)-latency from an ejaculation to the next intromission; and ejaculation frequency (EF)-the number of ejaculations in a test.

Behavioral estrus was induced in the females with intramuscular injections of $0.1 \mathrm{mg}$ estradiol benzoate $72 \mathrm{~h}$ before testing and $1.0 \mathrm{mg}$ progesterone $3 \mathrm{~h}$ before testing. Receptivity was confirmed with nonexperimental males; only receptive females were used in the tests.

In addition to the copulation tests, "emotionality" ratings using the scale devised by King (1958) were made. Eleven postoperative ratings were made at 2 - to 3 -day intervals beginning with the third postoperative day.

\section{RESULTS}

Emotionality Tests

Kruskal-Wallis one-way analyses of variance (Siegel, 1956) were performed on the aggregate emotionality scores (cf. King, 1958) of septals, sham operates, and normals. Significant differences were found with the septal group showing highest emotionality in both the first and second postoperative weeks $(\mathrm{S}=14.0, \mathrm{df}=2$, $\mathrm{p}<.001 ; \mathrm{H}=7.89, \mathrm{df}=2, \mathrm{p}<.02)$.

Copulation Tests

The only failures to intromit occurred for two Ss in the septal group on their first postoperative tests and on an additional test 2 weeks later. As these animals did mate on the second postoperative test and on an additional test 2 weeks later, their data are included in the statistical analyses.

Complete data from this experiment are too ex tensive to be presented in a brief table. Therefore, data on EF and on all measures in the first series are presented in Table 1 as a representative sample. Kruskal-Wallis analyses of variance (across all three groups) were performed on the data from each measure for each of the first five and the last copulatory series. Only four significant differences were found $\left(\mathrm{EL}_{2}, \mathrm{MIII}_{2,3}\right.$, $\mathrm{PEI}_{2}$ ). Specific comparisons of the septal and control operate groups with MannWhitney U tests (Siegel, 1956) revealed that the septal and control operate groups did not differ significantly on any of these measures. Thus, there appear to be no significant differences in copulatory behavior as a function of the septal lesions. No unusual aggressive behavior by the septal males toward the females was observed.

Histological Results

Combined reconstructions for all lesioned Ss indicated that the mean percentage of 
bilateral destruction of the medial and lateral septal nuclei was $88 \%$ and $78 \%$, respectively. No Ss received less than a $99 \%$ complete lesion in the anterior one-third of both the medial and lateral septal nuclei; more posterior sparing of these nuclei was generally found. However, the lesion procedures removed $97 \%$ of both nuclei in one $S$.

In some $\mathrm{Ss}$, incidental bilateral damage was found in the anterior portions of the lateral preoptic area, anterior portion of the diagonal band of Broca, and anterior portion of the lateral parolfactory area (nucleus accumbens septi). Extensive damage to the anterior cingulate cortex and corpus callosum was found in one S. Slight damage to the ventricular wall of the caudateputamen may have occurred in some animals. ${ }^{4}$

\section{DISCUSSION}

We have no explanation of the behavior of the two septals which failed to make an intromission on the first postoperative test. Examination of the lesions failed to suggest any anatomical basis for the performance of these two animals, though it is possible that a transient edema may have been a contributing factor. The females used with these two Ss gave positive indications of behavioral estrus both before and after the tests. During the unsuccessful test sessions, both animals were active and each followed the female and engaged in considerable anogenital sniffing. Neither male showed any signs of aggression toward, or fear of, the female. In fact, although septals were still scoring substantially higher than controls on the King scale (King, 1958) at the time the postoperative sex tests were given, we saw no sign of exaggerated social response to the estrus females on the part of any of the septal males.

Although septal lesions appear to alter other classes of social behavior in rodents (e.g., Bunnell et al, 1965, 1966b; Goodman et al, 1967) they do not have any appreciable effect on sexual behavior in the male laboratory rat as assessed under the present conditions. It appears that the changes in sexual behavior produced by insult to other parts of the limbic forebrain are independent of the integrity of the septal region lesioned in this study. Whether this will be true for species other than the rat awaits further study.

\section{REFERENCES}

BEACH, F. A., \& JORDAN, L. Sexual exhaustion and recovery in the male rat. Quarterly Joumal of Experimental Psychology, 1956, 7, 121-133.

BERMANT, G., GLICKMAN, S. E.. \& DAVIDSON, J. M. Effects of limbic lesions on copulatory behavior of male rats. Joumal of Comparative \& Physiological Psychology, 1968, 65, 118-125.

BUNNELL, B. N., SODETZ, F. J., \& SHALLOWAY, D. I. The effects of septal and amygdaloid lesions on aggressiveness and social dominance in the hamster. Paper read at the

Table 1

Mean Scores on EF and all First Series Measures and Corresponding Values of $\mathrm{f}$ for Kruskal-Wallis One-Way Analyses of Variance of Preoperative-Post Operative Shift Scores for Septal, Control Operate and Normal Control Rats

\begin{tabular}{|c|c|c|c|c|c|c|c|}
\hline \multirow[b]{2}{*}{ Measure } & \multicolumn{2}{|c|}{ Septal } & \multicolumn{2}{|c|}{ Sham } & \multicolumn{2}{|c|}{ Control } & \multirow[b]{2}{*}{$\mathrm{H}^{*}$} \\
\hline & Preop & Postop & Preop & Postop & Preop & Postop & \\
\hline ML & 41.2 & 61.0 & 125.6 & 59.6 & 13.4 & 9.9 & 1.31 \\
\hline IL & 123.0 & 128.6 & 193.4 & 65.4 & 25.2 & 41.2 & 1.39 \\
\hline $\mathrm{EL}_{1}$ & 388.0 & 464.8 & 430.4 & 340.2 & 430.0 & 299.9 & 2.31 \\
\hline$I F_{1}$ & 8.8 & 9.2 & 10.5 & 10.7 & 10.1 & 7.6 & 5.29 \\
\hline$M F_{1}$ & 3.6 & 8.9 & 6.2 & 3.3 & 5.1 & 4.8 & 4.02 \\
\hline $\mathrm{MIII}_{1}$ & 39.4 & 52.1 & 38.6 & 35.8 & 43.8 & 40.2 & 1.52 \\
\hline $\mathrm{PEI}_{1}$ & 325.2 & 302.1 & 336.2 & 331.4 & 342.0 & 335.2 & 1.16 \\
\hline $\mathbf{E F}$ & 7.4 & 6.5 & 7.4 & 7.1 & 7.3 & 7.1 & .50 \\
\hline
\end{tabular}

* $H .05$, df $2=5.99$

annual meeting of the Psychonomic Society, Chicago, October 1965.

BUNNELL, B. N., FRIEL, J., \& FLESHER, C. K. The effects of median cortical lesions on the sexual behavior of the male hamster. Joumal of Comparative \& Physiological Psychology, $1966 \mathrm{a}, 61,492-495$.

BUNNELL, B. N., BEMPORAD, J. R., \& FLESHER, C. K. Septal forebrain lesions and social dominance behavior in the hooded rat. Psychonomic Science, 1966b, 6, 207-208.

DEWSBURY, D. A., GOODMAN, E. D., SALIS, P. J., \& BUNNELL, B. N. Effects of hippocampal lesions on the copulatory behavior of male rats. Physiology \& Behavior, 1968, 3, 651-656.

GOODMAN, E. D., JANSEN, P. A., \& BUNNELL, B. N. Four limbic lesions and maternal behavior in female hamsters. Paper delivered at Psychonomic Society meeting, 1967.

HEIMER, H., \& LARSSON, K. Impairment of mating behavior in male rats following lesions in the preoptic-anterior hypothalamic continuum. Brain Research, 1967, 3, 248-263. KING, F. A. Effects of septal and amygdaloid lesions on emotional behavior and conditioned avoidance responses in the rat. Joumal of Nervous \& Mental Disease, 1958, 126, 67-68.
LARSSON, K. Mating behavior in male rats after cerebral cortex ablations: I. Effects of lesions in the dorsolateral and the median cortex. Joumal of Experimental Zoology, 1962, 151, 167-176.

MICHAL, E. K. The effects of lesions in the limbic system on courtship and mating behavior of male rats. Unpublished doctoral dissertation, University of Illinois, 1965.

MacLEAN, P. D., \& PLOOG, D. W. Cerebral representation of penile erection. Journal of Neurophysiology, 1962, 25, 29-55.

SIEGEL, S. Non-parametric statistics for the behavioral sciences. New York: McGraw-Hill, 1956.

\section{NOTES}

1. This research was supported by Grants GB-6590 and GB-4604 from the National Science Foundation and Research Fellowship 1-F2-MH 37, 424-01 from the National Institute of Mental Health.

2. Present address: Department of Psychology, Emory University, Atlanta, Ga. 30322.

3. Present address: Department of Psychology, University of Georgia, Athens, Ga. 30601.

4. Histological reconstructions may be obtained from the first author.

\section{Drinking following carbachol stimulation of hippocampal formation or lateral ventricies}

\section{DAMON MOUNTFORD, The University of Kansas, Lawrence, Kans. 66044}

Direct application of carbachol to the hippocampal formation of rats produced larger increases in drinking than did such applications to the adjacent lateral ventricles. This evidence appears to contradict the hypothesis that drinking following carbachol stimulation of the limbic system results from diffusion of the carbachol to active sites in or near the lateral ventricles.

Direct application of carbachol to a number of central nervous system sites, particularly in the limbic system, elicits drinking behavior (Grossman, 1960, 1964a, b; Fisher \& Coury, 1962; Coury, 1967). Since many of these sites lay near the midline, it was suggested that carbachol may diffuse from the limbic system into the ventricles where it may then act to elicit drinking (Routtenberg, 1967). Some substances, e.g., dopamine, diffuse rapidly from their site of application and, in some cases, concentrate in and around the ventricles (Routtenberg et al, 1968).

Fisher \& Levitt (1967) reported that sites where carbachol elicits drinking lie, in many cases, further from the ventricles than 